\title{
High-Speed Railway Traction Power Supply Equipment Condition-Based Maintenance Decision Model Based on Reliability
}

\author{
Hang Liu* and Qunzhan Li
}

School of Electrical Engineering, Southwest Jiaotong University, Chengdu, 610031, China

\begin{abstract}
Traction power supply equipments are the core part of the high-speed railway, so the maintenance of the power supply system is crucial for the security of the railway. Based on the research on the durable years of the traction power supply equipments, this paper puts forward the model of testing the traction power supply equipments of the reliable high speed railway. Some practical researches have proved that the model testing the traction power supply equipments of the reliable high speed railway can make the right decisions of detecting the failures of the equipments, so that a lot of time can be saved and much or insufficient maintenance can be avoided.
\end{abstract}

Keywords: Decision model, Equipment maintenance, Reliability, Traction power supply.

\section{INTRODUCTION}

Traction power supply system is the core part of the high-speed railway, of which the operating status will directly affect the safety and operation of the high-speed railway $[1,2]$. The supervision and the maintenance of the power supply ensure the safe operation, high effectiveness and prolong usage years. Nowadays, we are living in an era of high mechanization, complication and automation. However, the following shortcomings of the traditional maintenance (the posterior maintenance and periodic maintenance etc) have been revealed: the increasing difficulty of the daily maintenance and failures inspection; and the rising costs of the maintenance fees. The results caused by the traditional maintenance are serious because of the huge economic damages of stopping the machines and high maintenance fees [3]. With the developing testing technology, computer application technology and failures analyzing technology, the sensor technology and the condition based maintenance have been developed rapidly and also the superiorities have also been displayed $[4,5]$. Owing to the ability of testing the equipments conditions, predicting the durable years of the equipments by analysing the data and decision making technology, practicing the exact maintenance, ensuring the safe equipments' operation, prolong the durable years, saving the maintenance fees and improving the usability, the CBM (condition-based maintenance) theory has been the hot issue of the maintenance theory and research application field [68]. In order to further promote the application of CBM theory on the traction power supply system, this paper researches on decision making model of the reliable equipments' condition maintenance $[9,10]$.

*Address correspondence to this author at the School of Electrical Engineering, Southwest Jiaotong University, Chengdu, 610031,

China; E-mail: 249449722@qq.com

\section{THE IMPLEMENTMENTATION OF THE CBM EQUIPMENT}

The crucial factor of carrying out the CBM plan is to exactly analyze and predict the equipments' conditions. The outstanding effect of carrying out the CBM plan is the exact judgment of the equipment conditions and the timely discoveries of the equipments failures, which prevents accidents from happening. In this way, the purpose of reducing the maintenance cost and improving the profits brought by the equipments can be achieved $[11,12]$.

\subsection{Potential Failures and the P-F Interval Analysis}

Generally speaking, an equipment failure, including the generating period and developing period, happens often. And the failures caused by moving, grinding, erosion, aged failure, rupture and maladjustment and some other reasons may be especially more outstanding. As a result, according to the failure development period and the failure definition which shows the failure to do some certain things or conditions and the disabilities of doing the same things, the failures can be divided into the potential failures and the functional failures.

Functional failures refer to the disability of completing the reordered events or conditions. In order to be sure of the exact functional failures, one should be clear of the whole functions of the equipments. Because the system may have different functional failures, it is necessary to consider all the functional failures of the specific equipment in advance while analysing the pattern of the equipment failures and its effects $[13,14]$.

But, the potential failures refer to the sign of identifying the functional failures. Thus, there are two meanings of the "potential" here:

(1) It refers to the product status in early functional failures rather than any status before the functional failures. 


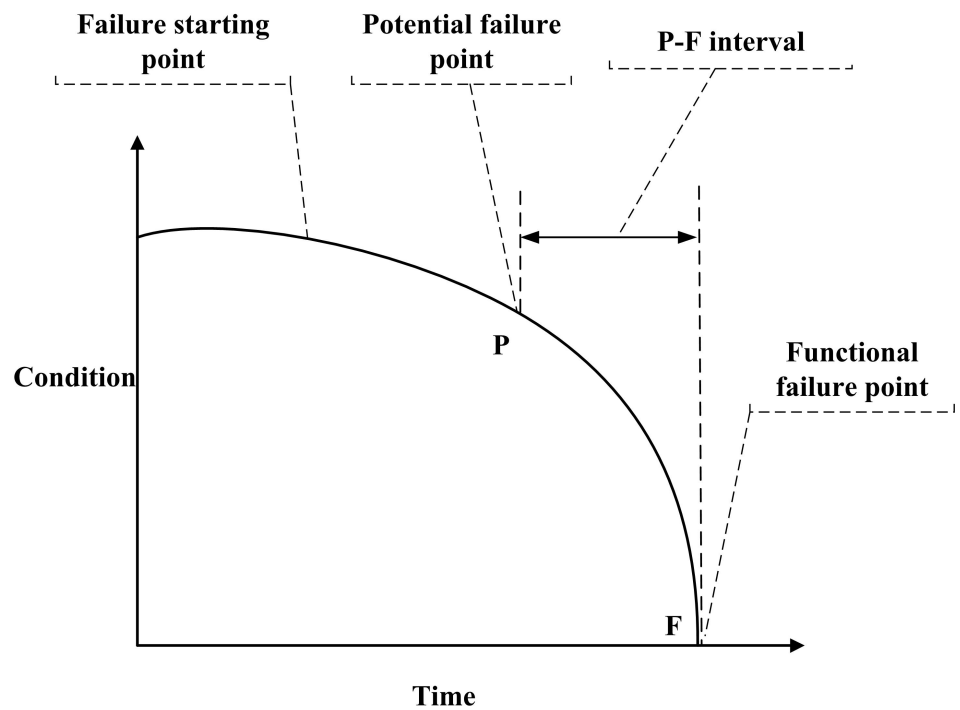

Fig. (1). P-F interval.

(2) The product status can be identified by observing and detecting. On the contrary, the product has no potential failures.

Most of the contacting nets undergo the process of transmitting from the potential failures to the functional failures; the failure pattern includes grinding, erosion, aging, rupture, maladjustment etc. The Fig. (1) shows the potential failures happening over time and it is called the P-F (Potential failure-Function failure) curve. This curve reflects the defect beginning time of a product to a failure detected at a certain time point (the potential failure point "P"). If the failure is not detected and corrected timely, the product failure will continue worsening till the functional failure of the time point "F".

In the process of failure development, the $\mathrm{P}$ point shows the failure is beginning or will begin is called the potential failure, and the period from $\mathrm{P}$ point to $\mathrm{F}$ point is called the potential failure occurring period. In practice, there are many ways of finding the failures of equipments (devices or parts).

In the Fig. (1), if the potential failure is detected during the period between $\mathrm{P}$ and $\mathrm{F}$, the corresponding measures can be used to avoid or prevent bad results caused by the functional failures. However, the chances of adopting some effective methods depend on the speed of failures. The job that mainly inspects the potential failures is called the CBM job. The CBM job refers to detecting the potential failures of an equipment so that an effective measure can be taken to avoid the functional failures and their consequences. The reason of calling it a CBM job is because an equipment can continue serving if it meets the standards of the performance indexes. This is also called as the preventative maintenance or the condition based maintenance. (Because, the failures are usually predicted based on the current equipment condition).

In recent years, the American army has put forward the theory of enhanced condition based maintenance $(+\mathrm{CBM})$ while exploring the theory of CBM and its application. "The enhanced condition based maintenance" refers to the improvement of the efficiency and profits of the equipment by comprehensively using advanced technologies based mechanisms, maintenance and information. "The enhanced condition based maintenance" can promote the unitization of the various activities in the fixing process; meanwhile it can effectively improve the responding ability of the equipment guarantee system. At present, the American army is estimating the feasibility of relative guidelines, projects, technologies and process. In the near future, "The enhanced condition based maintenance" will bound to be listed in the process of approving equipments' maintenance and purchase.

\subsection{The Feasibility Criterion of CBM}

Not all of the equipments (devices or parts) can implement the CBM. Based on the above analysis, it is advisable that the conditions of implementing CBM technology or the judgment criterions can be feasible only after meeting the below conditions:

(1) Be able to identify an obvious potential failure condition.

(2) To judge the feasibility according to the interval time less than that of the P-F.

(3) The rest P-F interval time must be long enough to take corresponding measures.

\subsection{The Crucial Technology of CBM}

The crucial technology of CBM is the condition monitoring, the failures diagnosis, includes prediction and the maintenance decision. The simple process is as the below Fig. (2).

To fully display the effects of the CBM, the CBM of the equipment should be the system and should be given the corresponding basic functions. At present, some foreign 


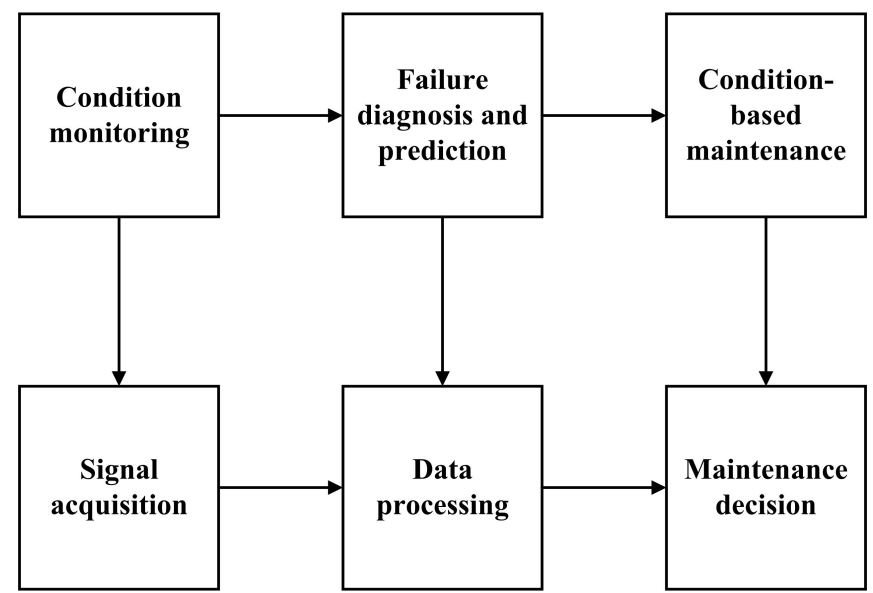

Fig. (2). The working procedure of the CBM.

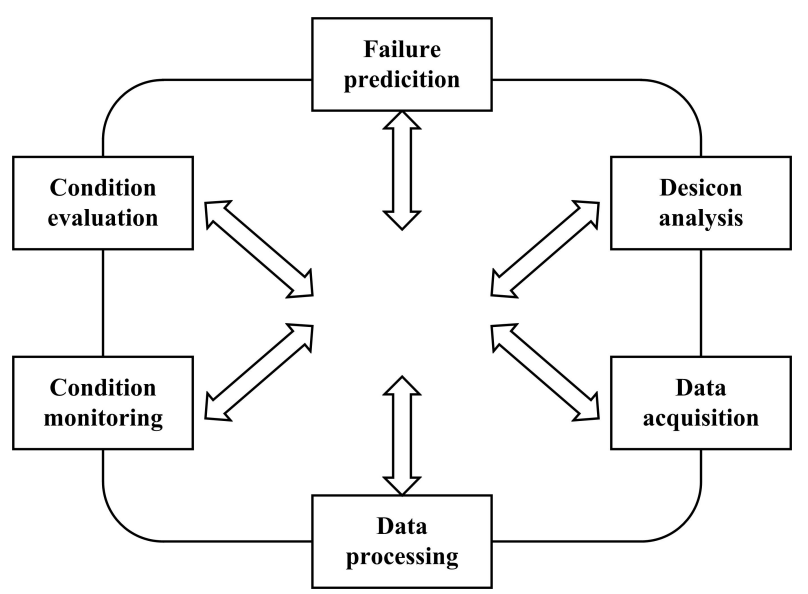

Fig. (3). The basic procedure of CBM system.

countries have studied about the CBM, although there are no clear concepts available, and there are lots of basic functions assigned to the CBM. As a matter of fact, it is to study the various function modules of $\mathrm{CBM}$ as a whole (namely the CBM system).

By analysing recent years study reports on the CBM, some progress and new discussion about the CBM procedure has come up. Such as Garga et al put forward a CBM system with modules of data processing, failure cataloguing and features summarizing, whereas Discenzo et al. identified 9 modules of CBM including the data accessing, condition detecting, failure detecting, failure predicting, prediction and control, systematically prediction and control, dynamic perfection, multi-aims control and new construction or selfadjustment.

So, according to the analysis, the above CBM system procedure Fig. (2) has been revised into a net-frame universal procedure Fig. (3) fitting the high speed railway power supply system which makes each module independent and connected to each other. The improved Figure is as follows:

\section{ON THE STUDY OF SINGLE CONDITION IN- FORMATION OF THE CBM MODEL}

The single condition information CBM model is an analysing and decision making CBM model constructed by the information of the certain equipment under certain situations (or feature's parameter).

\subsection{Model Hypothesis and Explanation of the Symbols}

Firstly to make the following hypotheses:

(1) The detecting time of a product is not fixed and on these unfixed time point the product information can be gained.

(2) The product durable years can be divided into two phases: the first phase starts from the beginning time to the potential failure time; the second phase starts from the potential failure time to the product expiration time, generally the second phase is called the prolonged time phase.

(3) The rest time of the product and the information observed are only related to the prolonged time phase. 
Table 1. Inspection Date Table.

\begin{tabular}{|c|c|}
\hline Inspecting Time & The Data Measured \\
\hline \hline The first week & 3.3513 \\
\hline The second week & 3.9555 \\
\hline The third week & 3.757 \\
\hline The fourth week & 3.8773 \\
\hline The fifth week & 4.0966 \\
\hline The sixth week & 8.3994 \\
\hline
\end{tabular}

$$
\begin{aligned}
& p\left(x_{0}\right)=p\left(x_{0} \mid Y_{0}\right)=\alpha \beta\left(\alpha x_{0}\right)^{(\beta-1)} e^{-\left(\alpha x_{0}\right)^{\beta}} \\
& p\left(y_{i} \mid x_{i}\right)=\alpha_{i} \eta\left(\alpha_{i} y_{i}\right)^{(\eta-1)} e^{-\left(\alpha_{i} y_{i}\right)^{\eta}} \\
& \frac{1}{\alpha_{i}}=A+B e^{-C x}
\end{aligned}
$$

$\mathrm{A}, \mathrm{B}$, and $\mathrm{C}$ are the parameters waiting for data statistics.

Namely the conditional residual life distribution probability density function of the product is at the time point of $t_{i}$ and under the situation of knowing the conditions information.

$$
\begin{aligned}
& p\left(x_{i} \mid Y_{i}\right)=\frac{p\left(y_{i} \mid x_{i}\right) p\left(x_{i}+t_{i}-t_{i-1} \mid Y_{i-1}\right)}{\int_{0}^{\infty} p\left(y_{i} \mid x_{i}\right) p\left(x_{i}+t_{i}-t_{i-1} \mid Y_{i-1}\right) d x_{i}} \\
& =\frac{\left(x_{i}+t_{i}\right)^{\beta-1} \prod_{k=1}^{i}\left(A+B e^{-C\left(x_{i}+t_{i}-t_{k}\right)}\right)^{-\eta} e-\sum_{k=1}^{i}\left(y_{k} /\left(A+B e^{-C\left(x_{i}+t_{i}-t_{k}\right)}\right)\right)^{\eta}-\left(\alpha\left(x_{i}+t_{i}\right)\right)^{\beta}}{\int_{0}^{\infty}\left(z+t_{i}\right)^{\beta-1} \prod_{k=1}^{i}\left(A+B e^{-C\left(x_{i}+t_{i}-t_{k}\right)}\right)^{-\eta} e-\sum_{k=1}^{i}\left(y_{k} /\left(A+B e^{-C\left(x_{i}+t_{i}-t_{k}\right)}\right)\right)^{\eta}-\left(\alpha\left(x_{i}+t_{i}\right)\right)^{\beta} d z}
\end{aligned}
$$

(4) Both of the two phases are independent and interlinked to some distributions.

(5) In the delay time stage, the information got at the time point $t_{i}$ is a random value whose each factor has its own distribution function which is the rest time function of this product at the moment.

The explanation of some symbols:

$t_{i}$ means the $i$ detecting time point of a product in the prolonged time phase.

$x_{i}$ means the rest time of a product at the time of $t_{i}$

$y_{i}$ means the inspection information of a product at the time of $t_{i}$

$\mathrm{Y}_{\mathrm{i}}=\{\}$ means the historical data of condition information collected before $t_{i}$.

$\mathrm{p}\left(\mathrm{x}_{\mathrm{i}} \mid \mathrm{Y}_{\mathrm{i}}\right)$ means the distribution probability density function of the rest time of a product when a product is at the time $t_{i}$ and the condition information is $\mathrm{Y}_{\mathrm{i}}$.

$\mathrm{p}\left(\mathrm{x}_{\mathrm{i}} \mid \mathrm{Y}_{\mathrm{i}}\right)$ means the probability density function of a product when the rest time of it is $x_{i}$.

The relation between $\mathrm{x}_{\mathrm{i}}$ and $\mathrm{x}_{\mathrm{i}-1}$ is as below:

$x_{i}=\left\{\begin{array}{l}x_{i-1}-\left(t_{i}-t_{i-1}\right) x_{i-1}>t_{i}-t_{i-1} \\ \text { no defition, else }\end{array}\right.$

\subsection{The Distribution of the Conditional Residual Life}

In 1995, in their issued essay, Wang, Christer and Sharp have defined the conditional residual life as following: conditional residual life refers to the time period between the detecting time point and the expiration time of the product, meaning the rest time of a product at some certain time point not only depends on its age but also relies on the condition information gained at the expiration time.

As for the single condition information model, if a product has a distribution probability density of $\mathrm{p}\left(\mathrm{x}_{0}\right)=\mathrm{p}\left(\mathrm{x}_{0} \mid \mathrm{Y}_{0}\right)$ and the condition distribution probability density belongs to the Weibull distribution (as for most of the mechanic products the Weibull distribution better suits for the delay time distribution). Namely:

In this equation, several parameters are included:

$\alpha, \beta$ are the parameters of the Weibull distribution; A,B, $\mathrm{C}$ are the parameters decided by some specific data and the relevant parameters estimated by the maximum likelihood estimation according to the observation data of product rest time and condition monitoring information.

\section{THE MAINTENANCE DECISION MODEL BASED ON THE RELIABLE REQUIREMENTS}

The equipment should be operated under the reliability of $\mathrm{R}_{0}$. In the process of operation, the reliability of the equipment is:

$R(t)=1-p\left(x_{i}<t-t_{i} \mid Y_{i}, t_{i}\right)$

The $\mathrm{p}\left(\mathrm{x}_{\mathrm{i}} \mid \mathrm{Y}_{\mathrm{i}}, \mathrm{t}_{\mathrm{i}}\right)$ is the rest time distribution probability density function at the time point of $t_{i}$. The $R(t)=R_{0}$, the value is $t$. if this value is beyond the time period $\left(t_{i}, t_{i+1}\right)$, there is no precaution change; otherwise, the precaution change should be carried out within the planning time.

The above model constructed is based on the math theory foundations. With a lot of data, complicated computing and difficult solving failures, the computer can be taken as an advantage for solving the failures. The decision making maintenance method can be gained after operating the computer programming and the data input.

The decision making maintenance making use of this method is used as following:

Given that the normal operation of connecting net system requires that the reliability is no less than $95 \%$.

To test the periodic conditions, the data gained by inspection is given in the Table 1. Because the testing period is one week, the testing unit used is the week to make it easy for computing. 


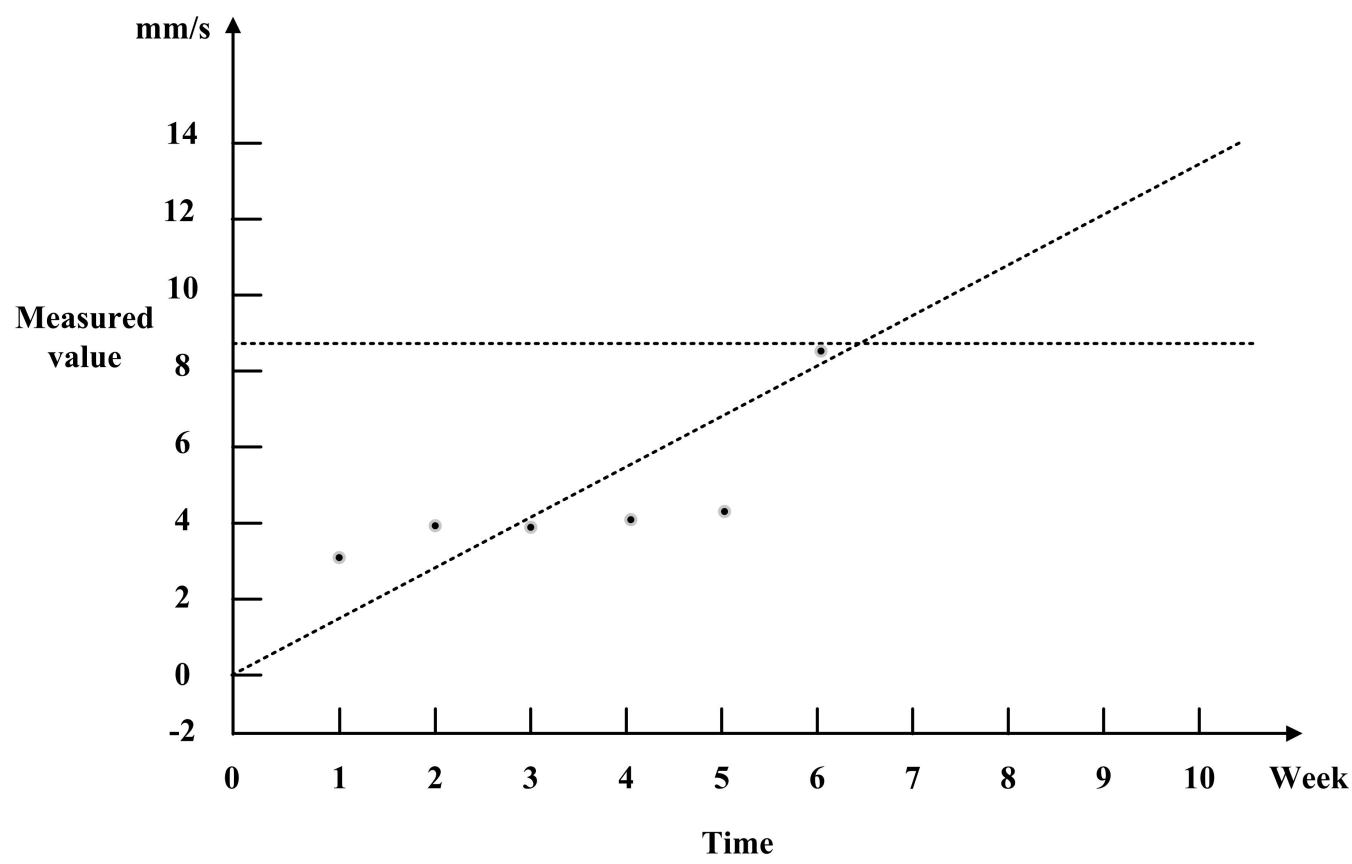

Fig. (4). The simulation result of decision making maintenance.

In the sixth week, the measured data (vibration amplitude) is 8.3994 to estimate if the part needs the precaution changes. The simulation result of the decision making maintenance is based on the reliability and the operation of the program, given in the following Fig. (4).

The regression equation of one variable of y vibration amplitude at the time of $\mathrm{t}$ is $\hat{y}=-0.1781+1.3574 t$.

According to the regression equation, the functional failure time $t$ can be worked out:

When the $y=8.3994$ and the $t=6.4$ (week). This value is within the time period $\left(t_{6}, t_{7}\right)$, so, the precaution change should be carried out in this time period.

According to the Fig. (4), the best maintenance period should be operated within the $\left(t_{5}, t_{6}\right)$.

\section{CONCLUSION}

The equipment based on the condition maintenance is the precaution maintenance technology, which can overcome the failures of sufficient and no maintenance. This definitely will bring great economic profits to the railway transportation. As a result, the condition maintenance is a new maintenance policy put forward and explored by domestic and foreign countries.

The CBM adopts the different maintenance patterns according to different equipments, which benefits in the operation improvement rate and the failure reduction rate. By ana$\log$ simulation, this paper proposes the policy making result which is based on the reliable purposes and helps to make an exact decision making maintenance.

\section{CONFLICT OF INTEREST}

The authors confirm that this article content has no conflict of interest.

\section{ACKNOWLEDGEMENTS}

This research is supported by 2014 China Railway Corporation Technology Research and Development Project.

\section{REFERENCES}

[1] J. Cao, The Railway Traction Power Supply System, Beijing: China Railway Press, 1983. (in Chinese)

[2] Q. Li, and J. He, Analysis on the Traction Power Supply System, Southwest Jiaotong University Press, 2007. (in Chinese)

[3] J. Wu, Pantograph and Contact Network System, Southwest Jiaotong University Press, 2010.12: 305(in Chinese)

[4] X. Jia, On the Decision Making Model Focusing on the Reliability, The National Defense Press, 2007. (in Chinese)

[5] Y.J. Ren, and D.N. Prab Murthy, On Management of the Maintenance Decision-Making Model, Science Press, 2008.

[6] Q. Yang, Z. and Li, S. Zhang, "Development of High Speed Railway Traction Power Supply Computer Repair Management System", Railway Computer Application, vol. 20, no. 8, pp. 26-29, 32, 2011. (in Chinese)

[7] J. Qi, S. Li, and B. Chen, "Preventive Maintenance Model Based on Reliability and Effectiveness", Aviation Precision Manufacturing Technology, vol. 21, no. 1, pp. 43-46, 2013. (in Chinese)

[8] Y. Zhang, H. Li, W. Sun, and L. Zheng, "Research on Radar Equipment Repair Decision Model of Economy - Based on Reliability”, Equipment Institute, 2013.(in Chinese)

[9] X. He, Z. Wang, and X. Chuo, "System Repair Model of the Whole Life Reliability Based on Time Varying", Chinese Mechanical Engineering, 2013. (in Chinese)

[10] G. Qi, On the Study of the Reliability and Security of the Contact Net of the High-Speed Railway, Southwest Jiaotong University Press, 2012. (in Chinese)

[11] Z. He, and H. Cheng, On the Study of the Safe Management of the High Speed Railway Traction Power Supply System and Warning System, vol. 10, pp. 259-264, 2012. (in Chinese) 
[12] Z. Liu, "On the Management System of the Contact Net and Practices". Railway Locomotives, vol. 1, pp. 66-67, 2007. (in Chinese)

[13] T.K. Ho, Y.L. Chi, 1. Ferreial, K.K. Leung, and L.K. Siu, "Evaluation of Maintenance Schedules on Railway Traction Power Sys- tems", In: Proceeding of the Institution of Mechanical Engineers, Part F: j. Rail and Rapid Transit, vol. 220, no. 2, pp. 91-102, 2006

[14] W. Yu, On the Contact Net of the High-Speed Electrified Railway, Southwest Jiaotong University Press. 2003. (in Chinese).

Received: September 16, 2014

(C) Liu and Li; Licensee Bentham Open.

This is an open access article licensed under the terms of the Creative Commons Attribution Non-Commercial License (http://creativecommons.org/licenses/by-nc/4.0/) which permits unrestricted, non-commercial use, distribution and reproduction in any medium, provided the work is properly cited. 